In conclusion, Dr. Kerr mentioned some recent changes in medical practice which he regarded as unfortunate. Among these he included reliance on X-ray examinations as short-cuts to diagnosis, without a thorough investigation of the history of the case and a complete physical examination. He also disapproved of the displacement of prescriptions by the indiscriminate use of the products of the manufacturing chemists, and he considered that vitamins were too often prescribed in concentrated form rather than in a good mixed diet as nature presents them to us.

Dr. George F. Whyte was elected President of the Association for session I936-37.

\title{
REVIEWS.
}

\section{TREATMENT IN GENERAL PRACTICE.}

The Management of some major Medical Disorders. "I."

B. M. J.

H. K. Lewis \& Co., LtD. 1936. $8 / 6$ net.

This series of 35 articles by well-known contributors represents a reprint in book form of articles which have already appeared in the "British Medical Journal." The articles are divided into three main groups, under the headings of respiratory and cardio-vascular diseases, and specific fevers. The subject matter is clearly set out, and in a rather dogmatic form which may be useful to the senior student or newly qualified practitioner, but many important lines of treatment do not receive mention; to have to limit the curative treatment of influenza to under three pages, as in the opening article, necessarily makes its description extremely brief. Useful lines of modern treatment are incorporated in some of the articles, especially those dealing with specific fevers, but in the main the material is such as has already found its way into many modern text-books of medicine : so that it is difficult to see the advantage of this special collection of articles.
STUDIES ON THE HEALING OF FRACTURES, with Special Reference to the Significance of the Vitamin Content of the Diet.

By John Hertz, M.D., Assistant Surgeon, Department C, Surgical University Hospital, Copenhagen. Lewin \& Munksgaard, Copenhagen; Humphrey Milford, Oxford University Press, London. 1936. pp. 286, figs. 82. Price 15/- net. (Trans. by Hans Andersen, M.D.).

The occurrence of delayed union, as well as the less frequent non-union of fractures, is a matter of practical interest to all surgeons engaged in active work. In cases where the cause is not far to seek the indications for treatment are correspondingly clear. But all surgical practitioners sooner or later meet with cases in which the causes are obscure. For that reason the findings which Dr. Hertz has just published will be read with interest.

Starting with the premise " that the vitamin content of the food affects in a greater or lesser degree the bones and the process of osteogenesis " the idea suggested itself to him "that the process of osseous regeneration, including the healing of fractures, may also be influenced by the vitamin content of the food." In order to investigate that question experimental studies were carried out on guinea pigs and on rats. The process of healing in animals 